\title{
Library Liberec
}

\author{
by RADIM KOUSAL
}

It is said that the difficulty with the project of the modern library consists of the coexistence of a bibliotheca and a mediatheca - the two worlds of a library, a library of the past and a library of the future.

How do we solve this problem? One way is the universal design, which is able to absorbe both of those worlds of the library and at the same time to have the capacity to absorbe the fluctuation of the library's program for the future.

So let's start at the beginning. In Liberec there was one of the biggest synagogues in central Europe. This synagogue was destroyed in 1938.

We can now see how the project has developed. There was a competition design. The synagogue was detached.

Then ULP - „urban land permi project“ - joined. At this stage the synagogue was integrated, and incorporated into the volume of the library.

And finally in the last stage the prismatic form of the synagogue was semidetached.

A library for the 3rd millenium is a universal, informational, textual and multimedial centre whose architectural space guarantees a high technical and architectural flexibility, and which is adaptable to changing requirements.

This universal space of the library is delimitated by the cylindric form of the roof and by the transparent and translucent facade. The open space of the library which is structured by several floors - decks - is built on the base where car parks, stocks, technical servicies and facilities are situated.

An accidental composition of the glazed facade reflects the transformation of the library's program. The facade is protected by a system of blinds and the transparency is able to express a perpetual changing of the library.

The simple, compact and dynamic form of the library exploits the controversy of the building site, as an expression of the library's function, according to the semantic signification of the architecture. 
The architectual composition of the library stands out in the media wall which is one of the first impressions for the visitor. The changing of the architectural container reflects the fluctuation of the library's function, and it expresses its contemporary state.

The front of the library, with the medial wall and the prismatic form of the synagogue, forms a semiclosed space of a small square. The library building is situated in the centre of Liberec, in the parallel urban axis, where the town hall, the theatre, the economical faculty etc. are situated.

The simple, closed, triangular form of the synagogue is inspired by the shape of the star of David. It's not by accident that the facade's stone clading of the synagogue resembles the wall of lamentations.

The daylight penetrates into the interior of the synagogue through only three openings. And it creates an atmosphere like that in a medieval synagogue in Prague.

The carved inscription of a verse from the Tora on a perimeter of the facade and the trace of the destroyed synagogue commemorate this tragical event.

The central space of the Jewish cultural centre is the triangular shaped synagogue which is surrounded by an oblique gallery. This gallery serves for ceremonies, exhibitions and pedestrian traffic. In the case of an orthodox ceremony the upper part of the gallery serves the women.

Back to the library: Society and individual are two phenomena which predetermine the two parts of the library - a social part and an educational part.

A visitor to the library can discover a world of information. The first information is on the media wall which ensures communication between the library and the city. Two integrated digital displays inform us about the program of the library, cultural events in the town and about other regional activities.

Graphic elements are also part of the building's identity. Clear internal orientation systems not only belong to the architecture, but are an indispensable visual graphic concept, comprising of both permanent and temporary information.

The world of information is open for visitors in the information centre of the library. The visitor is introduced to the milieu of the library. And then the visitor may go on to discover other worlds of the information - worlds of knowledge, discoveries, fantasy, sons etc.

The lobby is the central space of the library and it separates two parts of the library - the social part and the individual part. And this lobby also connects every departement of the library - the information centre, the 
exhibition hall, the universal library, the scientific library, the musical departement, the recording and audiovisual studio, the conference hall and the cafeteria. The transparency of this space can create synergical effects. One activity of the library can support another activity and so one. And of course two parts of the library stay independant in their own purposes.

Each deck of the library is articulated - broken up for zones: The zone of relaxation, the zone of inormation and the zone of concentration. The zone of relaxation, which is most active, forms a sort of floor axis. This zone is boarded by the zone of information where the inormation is stocked - books or other media. When we cross or traverse the information zone we find the zone of concentration - the calmest area in the library.

This zoning indicates a hierarchy and a structuring of the universal and flexible space of the library. Of course there is another level of the structuring, an invisible electronical level: A virtual world which is present at each structure of the library.

The new library is a platform for a virtual library and a platform for a mediatheca. For instance, there is an audiovisual studio, a recording and TV studio, an information centre for citizens, and it offers external access to the library's products. The library also gives a patronage to different cultural projects.

The new library is based on the philosophy that a library is an institution for information. We can say that the new library building is based on the conception that ,a library is the hypermarket for information“.

Organisation of the library's space, the furnishing, and the equipment of the interior, is a temporary status quo and it is one possibility for more solutions.

The cultural evolution, the evolution of society and technology will certainly change the concept of the library. It is essential that the universal space of the new library must absorb it.

I'd like to conclude with the words of Hannelore Jouly :

„A library is a place which must be continually restaged, so that visitors are confronted with the unexpected, finding not only what they were looking for, but also what they have never looked for - maybe a need to resolve a complex problem."

Radim Kousal

Architect

c/o Mgr. Vera Vohlídalová

State Research Library in Liberec

nám. Dr. E. Beneše 23

46053 Liberec 1, Czech Republic 
RADIM KOUSAL

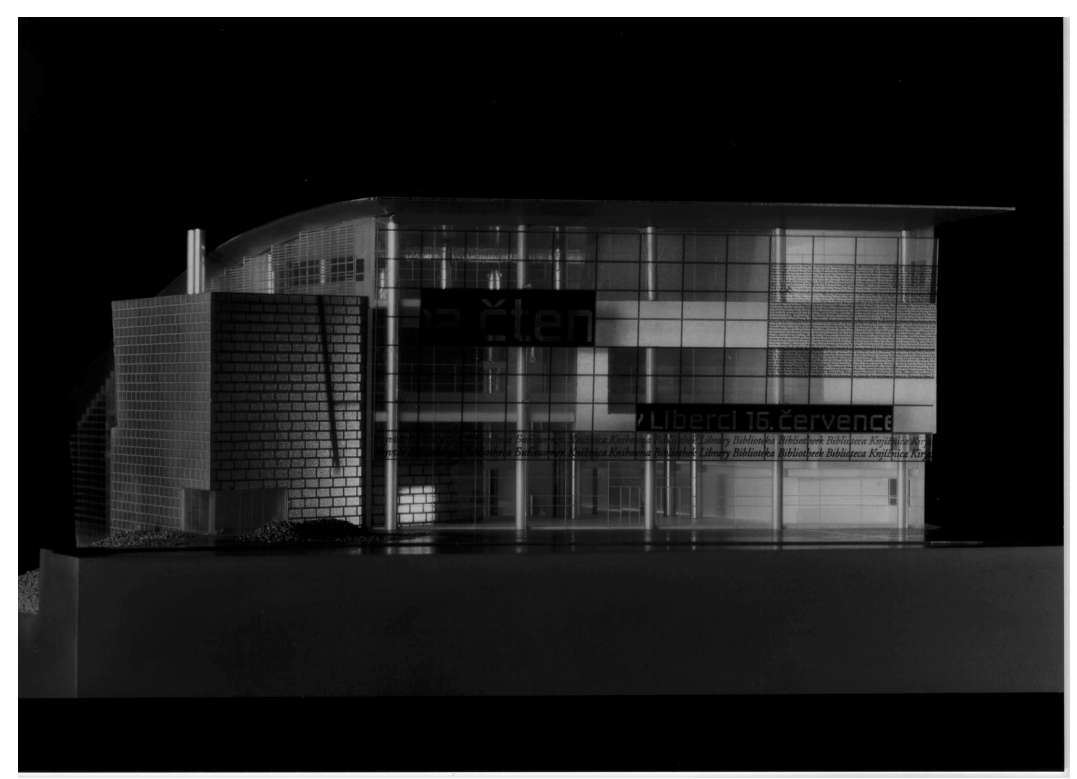

Figure 1

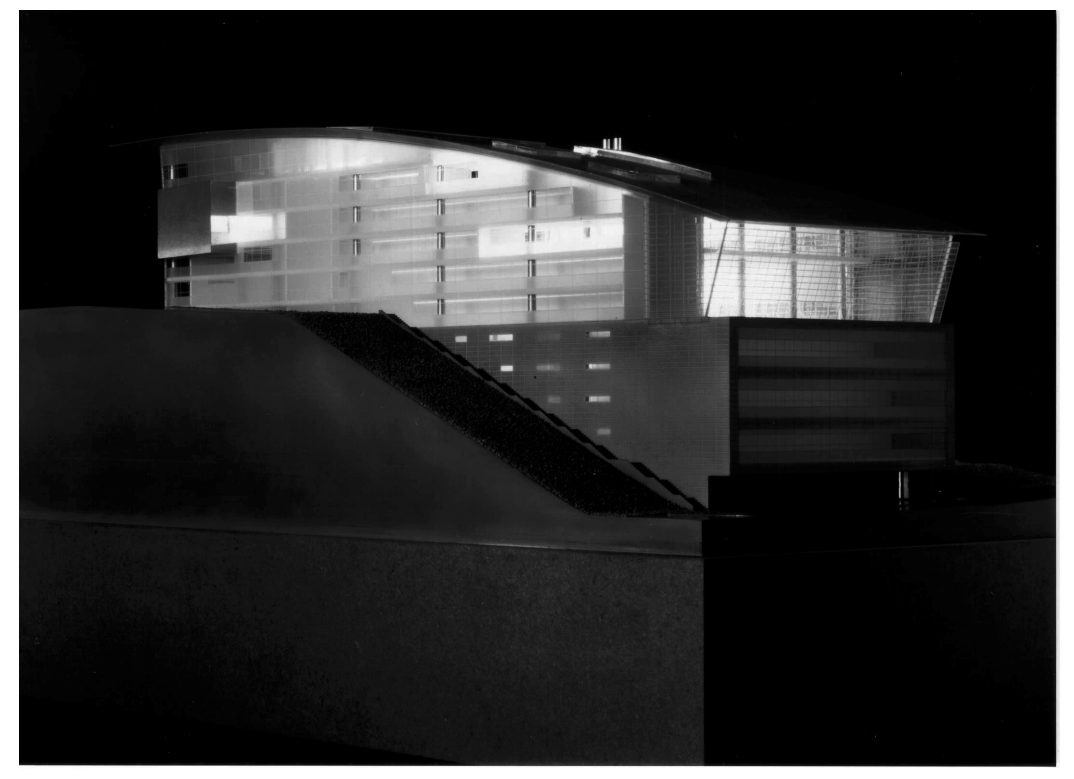

Figure 2 


\section{Library Liberec}

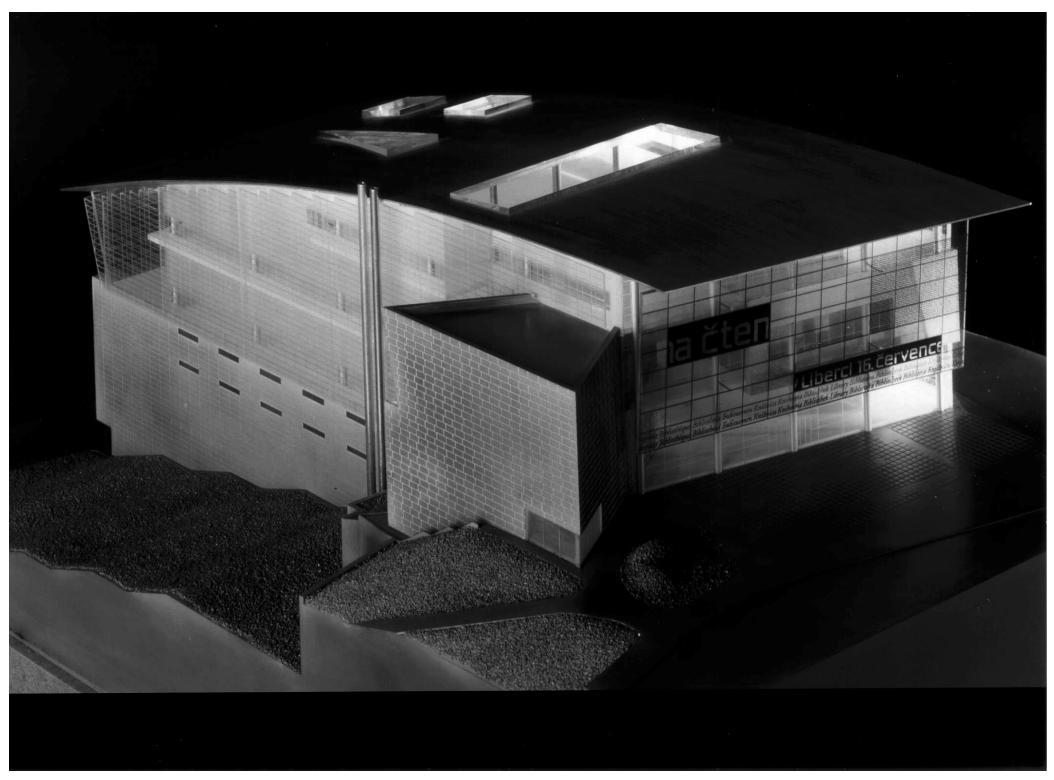

Figure 3

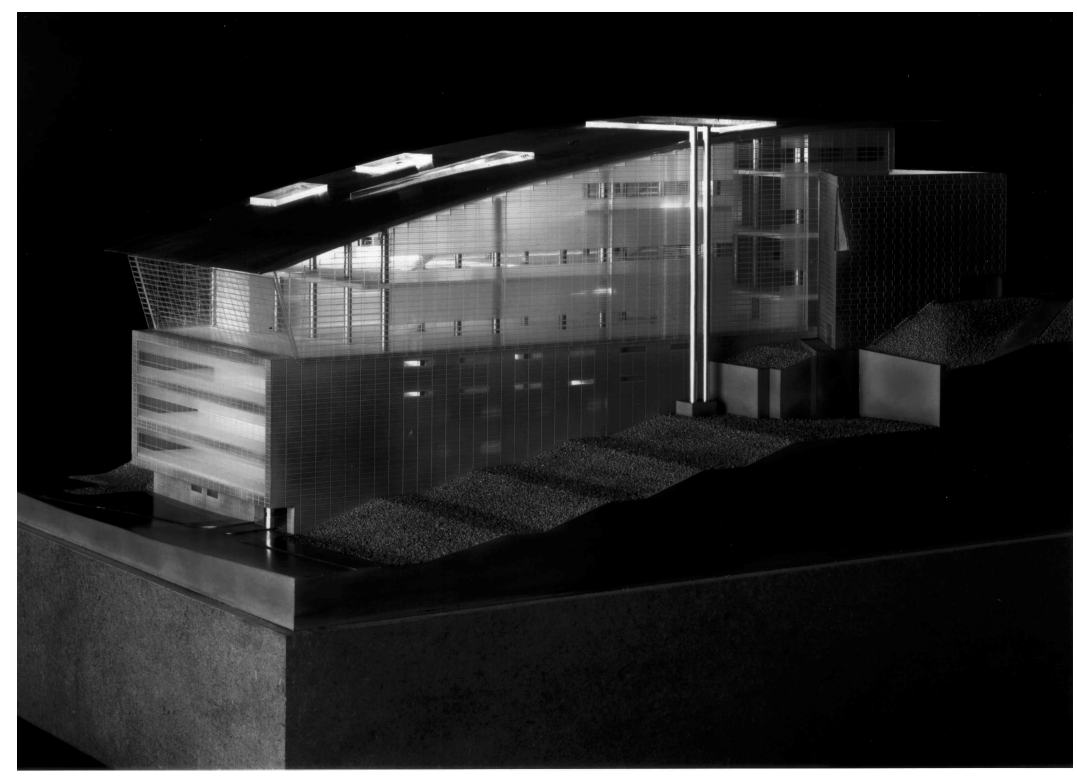

Figure 4 